\title{
Inflammatory Malignant Fibrous Histiocytoma Associated with Leukemoid Reaction or Leukocytosis: A Comprehensive Review
}

\author{
Jorge Hurtado-Cordovi, Prajwol Pathak, Boris Avezbakiyev, and Marianne Frieri \\ Divisions of Hematology and Oncology and Allergy and Immunology, Department of Medicine, Nassau University Medical Center and \\ North Shore- Long Island Jewish Health Care System, 2201 Hempstead Turnpike, East Meadow, NY 11554, USA \\ Correspondence should be addressed to Jorge Hurtado-Cordovi, inmuci1933@yahoo.com
}

Received 6 June 2012; Accepted 1 July 2012

Academic Editors: S. Mandruzzato and J. Tovari

Copyright (๑) 2012 Jorge Hurtado-Cordovi et al. This is an open access article distributed under the Creative Commons Attribution License, which permits unrestricted use, distribution, and reproduction in any medium, provided the original work is properly cited.

\begin{abstract}
Inflammatory malignant fibrous histiocytoma (IMFH) associated with leukemoid reaction (LR)/leukocytosis is a rare entity. In this paper, we search PubMed for all known cases of IMFH associated with LR/leukocytosis in an attempt to draw conclusions about this variant's response to treatments and its pathophysiology. Medline electronic database was searched using key words such as malignant fibrous histiocytoma, leukemoid reaction, and leukocytosis. A total of 16 patients were found, twelve males $(75 \%)$ and 4 female (25\%), with a mean age of 62.6 years, ranging from 47 to 77 . The mean survival was 770 days, ranging from 14 to 6570 days. Four patients were alive at last follow-up: 6570 days, 1095 days, 335 days, and 180 days, respectively. Of the 12 patients that expired, death occurred approximately 92 days after the onset of LR or leukocytosis, ranging from 3 to 334 days. We conclude that IMFH associated with LR/leukocytosis does not completely respond to chemoradiation. Overproduction of growth factors and cytokines by IMFH cells and their interactions with the inflammatory infiltrate seem to promote immunological effector cell's dysfunction and substantiate the development and growth of this neoplasm. A clear understanding of these molecular pathways is crucial in order to identify targets for potential therapy.
\end{abstract}

\section{Introduction}

Inflammatory malignant fibrous histiocytoma (IMFH), also known as undifferentiated pleomorphic sarcoma (UPS) inflammatory variant, was initially identified as a separate category by Kyriakos and Kempson in 1976 [1]. Its name is derived from its distinct histological pattern; an intense inflammatory infiltrate that may be composed of neutrophils, eosinophils, and/or lymphocytes without a recognized source of infection. These tumors are usually bulky, and their clinical course is characterized by multiple local recurrences, metastasis, and ultimately death. Due to its mesenchymal origins, this neoplasm can virtually affect any part of the body; however, they are most commonly encountered in the retroperitoneal cavity. Patients typically present with fever and other constitutional symptoms mimicking an infectious process, and/or a rapidly growing painful mass. In cases of retroperitoneal IMFH, patients can also present with additional signs/symptoms of a space-occupying lesion [2$6]$.
Conventionally, leukemoid reaction (LR) is defined as a secondary leukocytosis with a white blood cell count (WBC) that is frequently above $50 \mathrm{~K} / \mathrm{mm}^{3}$ resulting in a severe left shift with the presence of immature myeloid cells in the peripheral blood, but with clear distinction of polyclonality and no signs of maturation arrest. Although it resembles leukemia, the presence of this disease cannot be demonstrated during the course of the illness or postmortem. Nowadays experts agree that the WBC count does not necessarily have to exceed $50 \mathrm{~K} / \mathrm{mm}^{3}$ to be considered a LR as long as the parameters described above are met $[7,8]$. IMFH is universally associated with an elevated white blood cell count (WBC) composed mostly of neutrophils $[9,10]$. Due to the severe elevation in the WBC, some of these cases have been misdiagnosed as acute leukemias; however, bone marrow biopsy, when performed, typically shows hypercellularity without evidence of monoclonal proliferation $[1,9,11]$. A few reports have documented a normalization of the WBC count after removal of the primary neoplasm, and an increase to previous values or 
higher once the tumor relapses [12-17]. This finding suggests that IMFH is capable of releasing a variety of cytokines and growth factors which could contribute to the development of the LR/leukocytosis associated with it $[9,10,12,15,16$, $18,19]$.

The causes of the LR associated with this malignancy are not well understood since there are so few articles reported in the primary medical literature. In this paper, we search PubMed for all known cases of IMFH associated with LR or leukocytosis in an attempt to draw conclusions regarding this variant's clinical presentation, course, survival, available treatments, and the pathophysiology behind the LR/leukocytosis.

\section{Methods}

Medline (PubMed) electronic database was searched by two independent reviewers ( $\mathrm{JH}$ and $\mathrm{PP}$ ) using key words such as "malignant fibrous histiocytoma, leukemoid reaction, pleomorphic undifferentiated sarcoma inflammatory variant, and leukocytosis." Older nomenclatures for this tumor such as "xanthosarcoma, malignant fibrous xanthoma, and inflammatory fibrous histiocytoma" were included in our search as well. Other types of sarcomas and undifferentiated Sarcomas associated with leukemoid reaction or leukocytosis were excluded. Leukemoid reaction was defined according to the parameters described in the Introduction section. Leukocytosis was defined as a WBC two standard deviations above the mean with the predominance of a specific mature myeloid cell, lymphocyte, or monocyte. If the WBC was less than $50 \mathrm{~K} / \mathrm{mm}^{3}$, but a severe left shift was present, early myeloid cells were seen in circulation, polyclonality was identified, and there were no signs of maturation arrest; then it was considered as a leukemoid reaction. The results were screened according to but not limited to the following exclusion criterion: patient younger than 18, iatrogenic-related tumors (such as postradiation), tumor arising secondary to preexisting disease, synchronous or metachronous malignancies, and IMFH associated with a maximum WBC less than $24 \mathrm{~K} / \mathrm{mm}^{3}$.

\section{Results}

After a detailed search of Medline, according to the exclusion criterion described in the Methods section, we found 14 articles. One of the papers was a primary research article (Melhan et al.), one a case series (Kyriakos et al.), one a brief report (Algabra et al.), and the rest were case reports (Table 1). A total of 16 patients were described by these studies, $12(75 \%)$ males and $4(25 \%)$ females (Table 2). The mean age at presentation was 62.6 years with a range of $47-$ 77. A total of 8 tumors were located in the retroperitoneal space (50\%), 2 of them in solid organs outside the peritoneal cavity, 2 were found inside the abdominal cavity, 3 were located in the extremities/deep soft tissue, and 1 was confined to the dermis (Table 2). The most common presenting complaints were a combination of mass/pain in 13 patients $(81.2 \%)$ and constitutional symptoms in 7 patients $(43.8 \%)$ with weight lost and fever being the most common. The mean survival was 770 days, ranging from 14 to 6570 days. Four patients were alive at last followup: 6570 days, 1095 days, 335 days, and 180 days. Of those 12 patients that passed away, death occurred approximately 92 days after the onset of LR or leukocytosis, ranging from 3 to 334 days (Table 2).

\section{Discussion}

Inflammatory malignant fibrous histiocytoma $\backslash$ undifferentiated pleomorphic sarcoma inflammatory variant was first described over 30 years ago; however, due to the rarity of this entity, information about its presentation, clinical course, and outcome is very scarce. Unfortunately, our analysis is greatly limited by the small number of cases found in the primary medical literature. Taking this limitation into account, we attempt to draw conclusions regarding the clinical behavior of this neoplasm. Our results suggest that IMFH associated with LR/leukocytosis usually presents in the seventh decade, and up to $75 \%$ of the cases are seen in males. Thirteen patients $(81.2 \%)$ presented complaining of a combination of a mass and/or pain. Forty percent of these individuals complained of constitutional symptoms, weight lost and fever being the most frequent. Our study suggests that $50 \%$ of this variant arises from the retroperitoneal space. However, due to its mesenchymal origin, it is known that this neoplasm can virtually affect any organ $[20,21]$. The previous statement correlates with some of the cases described in which IMFH with/without LR has been detected in solid organs, intestinal tract, musculoskeletal tissue, and the integument $[12,14,17,19,22,23]$.

The overall survival observed varies greatly from case to case. Perhaps this finding portrays the different treatments, locations, and how advanced the disease was at presentation. The mean overall survival was 770 days with a range of 14-6570 days; four patients were alive at last followup (Table 2). Twelve patients passed away; on average, death occurred approximately 92 days after the onset of LR or leukocytosis. Our analysis shows that the severity of the leukemoid reaction correlates with the time of death. Close to the time of demise, in both of the cases reported by Melhan et al., the WBC increased above $150 \mathrm{~K} / \mathrm{mm}^{3}$. Although, patient number 2 in this study survived for more than 400 days; once his WBC increased to a 3 digit value, he quickly deteriorated and expired [9]. We reported a similar case of a 60-year-old white male that presented with a severe leukemoid reaction; his clinical course was highlighted by rapid deterioration and death occurring secondary to cardiovascular arrest. It is worth noticing that in both of these studies once the WBC went above $100 \mathrm{~K} / \mathrm{mm}^{3}$, the patients were not capable of tolerating any chemoradiation secondary to their unstable clinical condition. This observation reemphasizes the need for rapid detection and aggressive treatment in patients with this disease $[1,24-26]$.

On the other hand, of those 4 patients that were alive at last followup, it was observed that their WBC never increased above $50 \mathrm{~K} / \mathrm{mm}^{3}$. Asirwatham and Pickeren reported a case that survived for 18 years (Table 1). The 


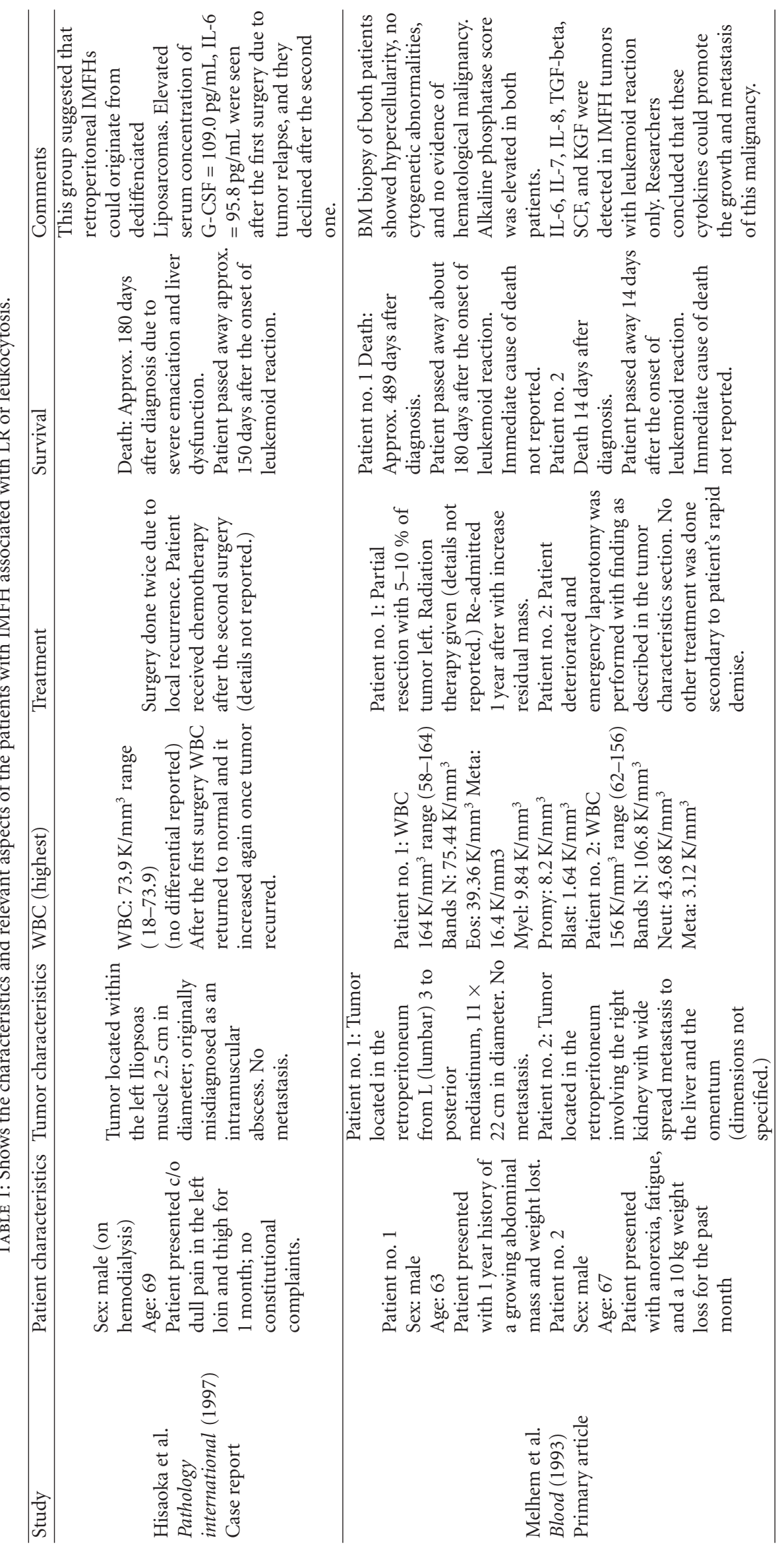




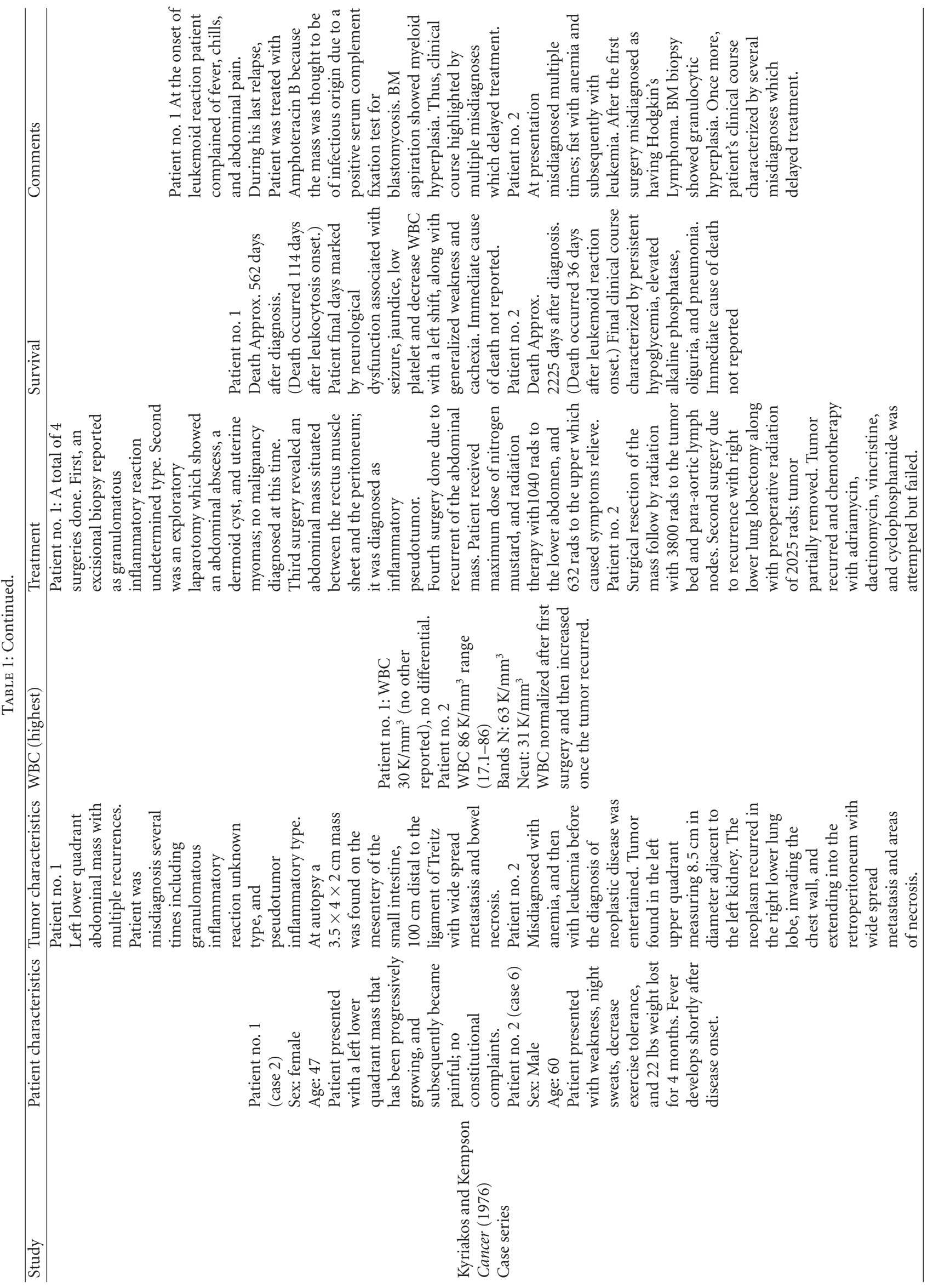




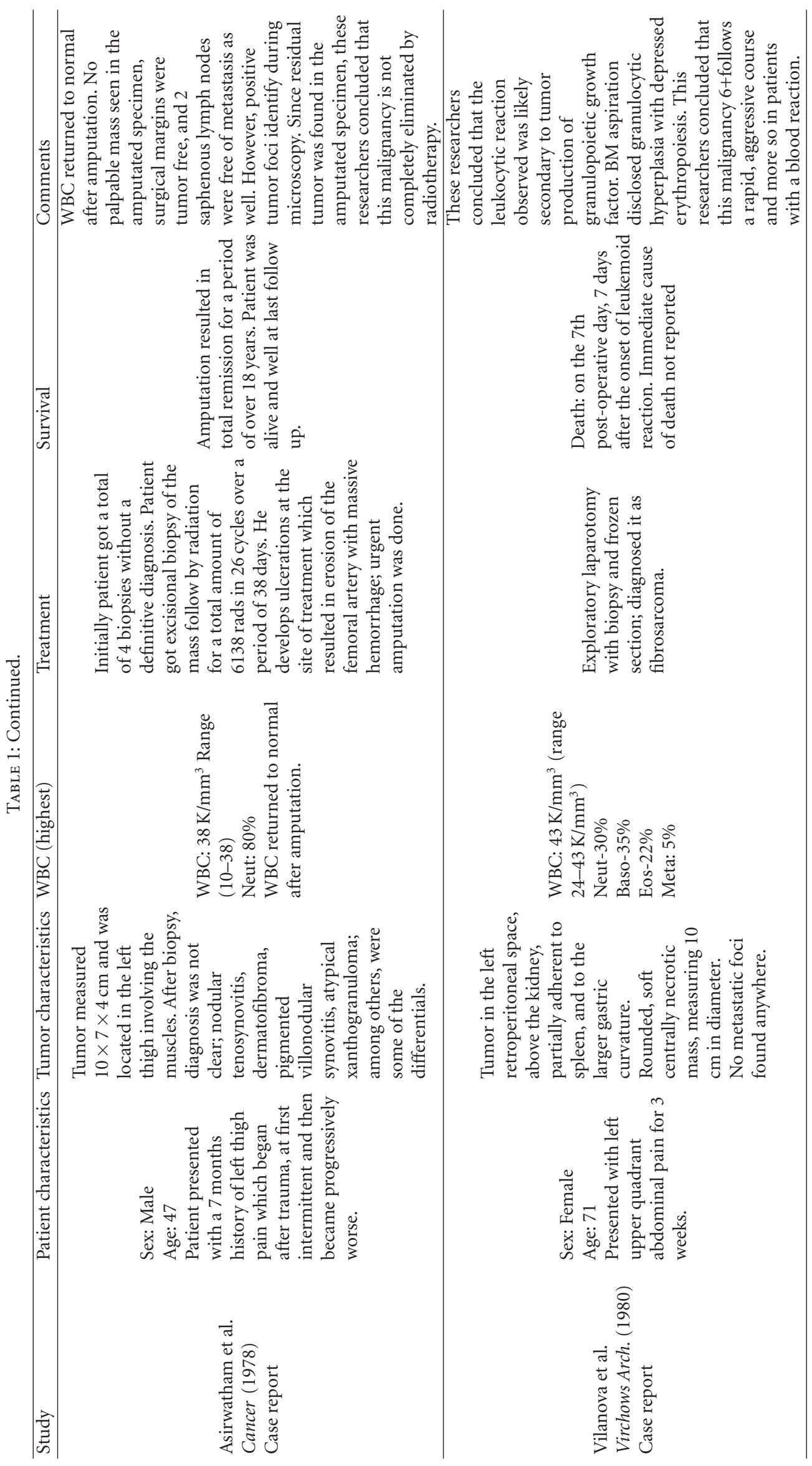




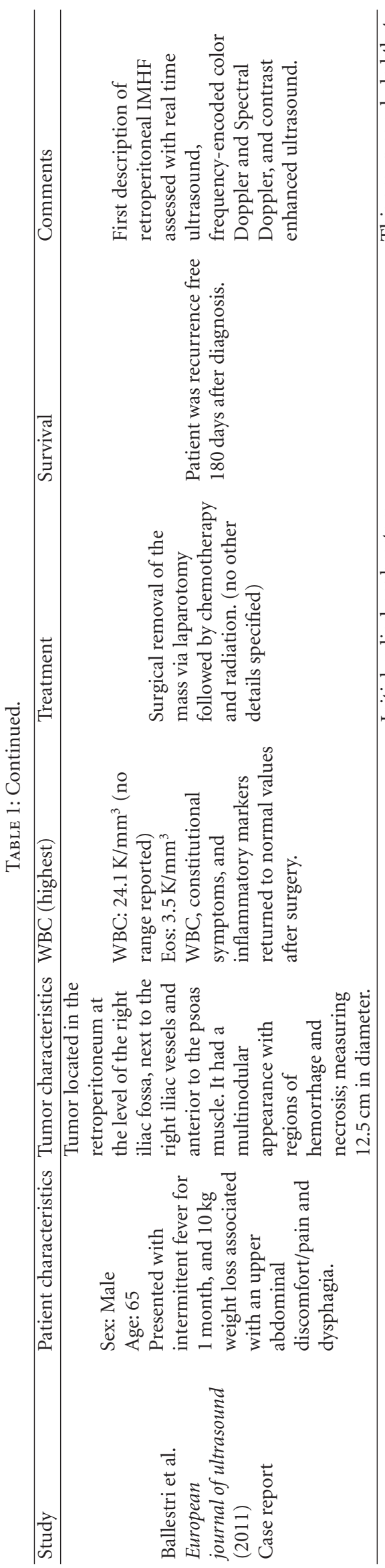

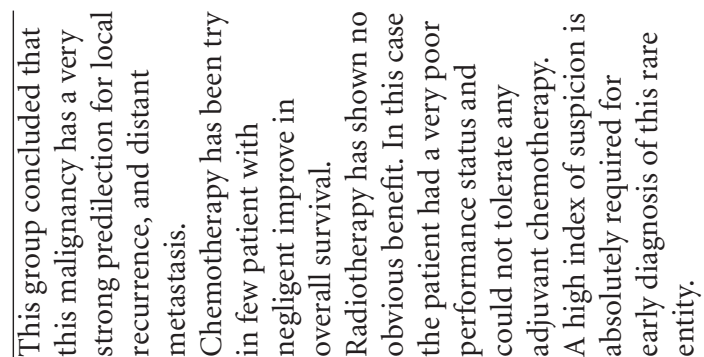
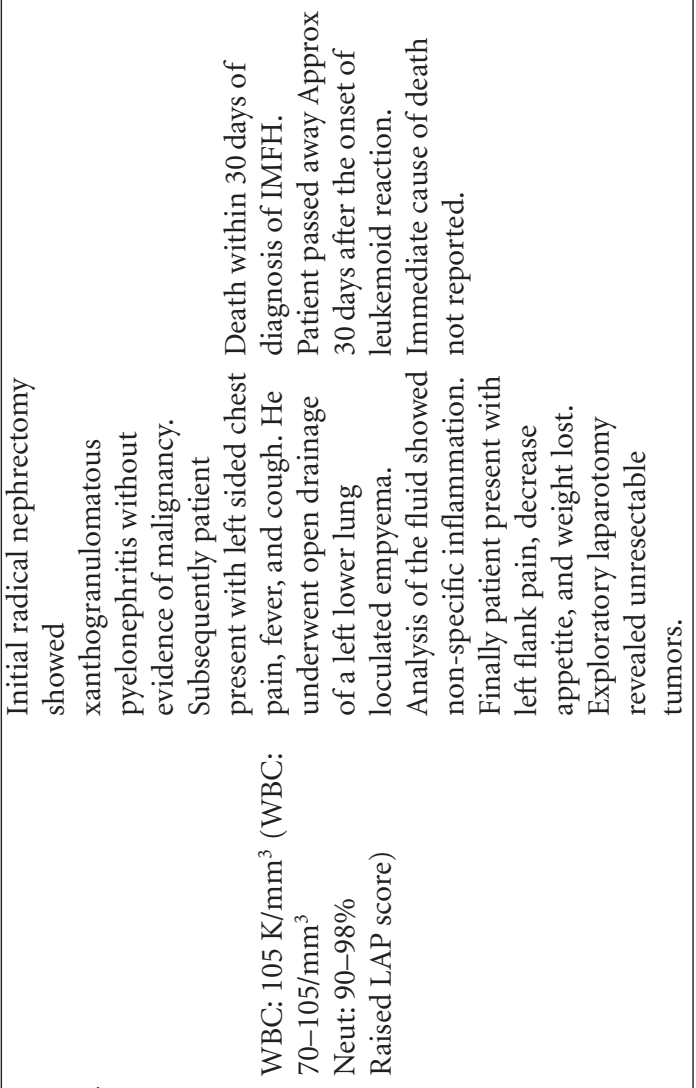

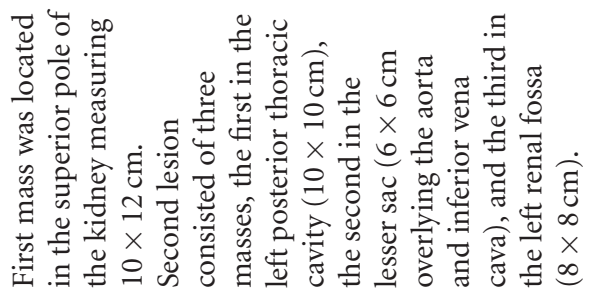

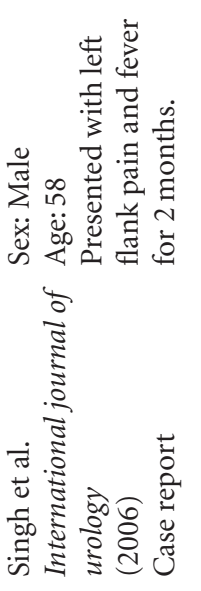




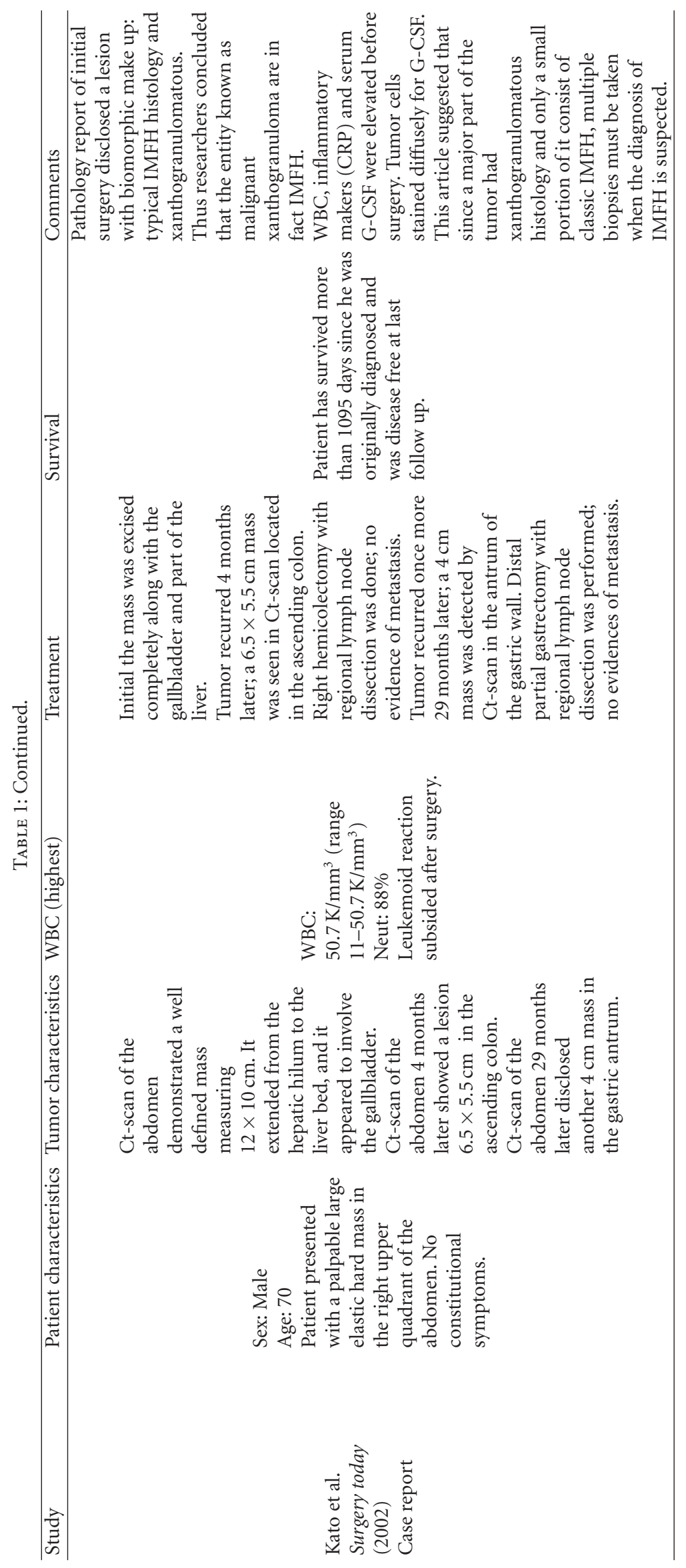




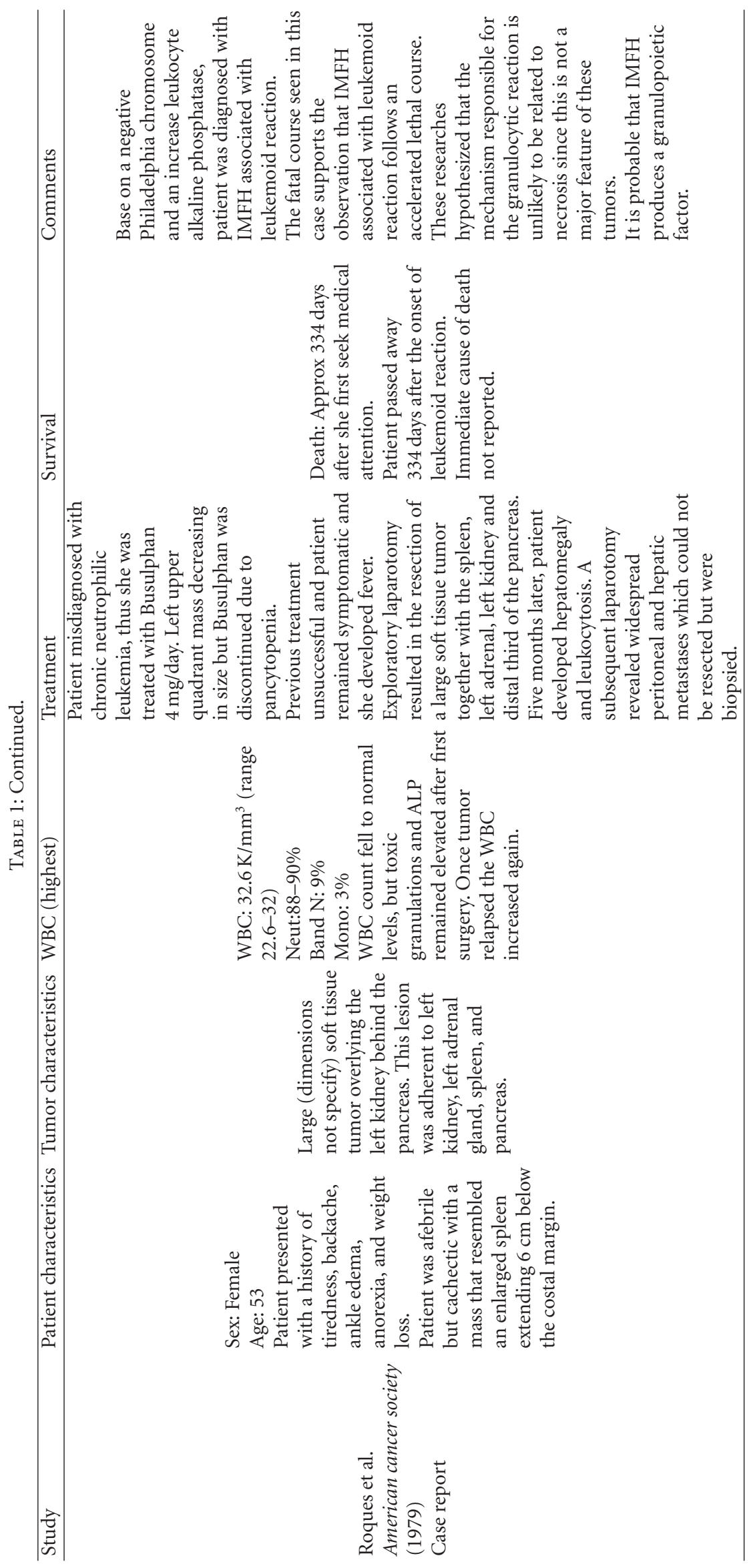




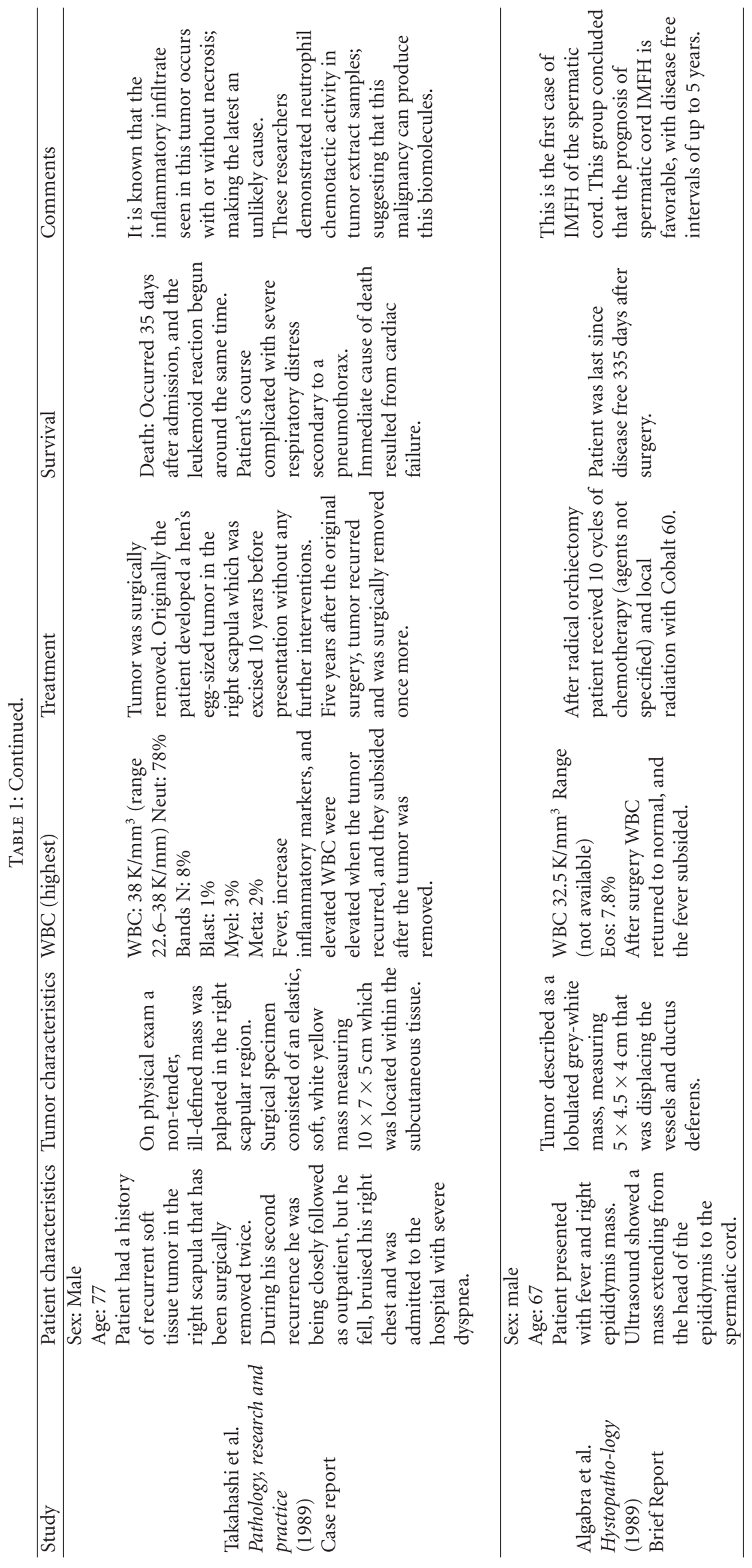




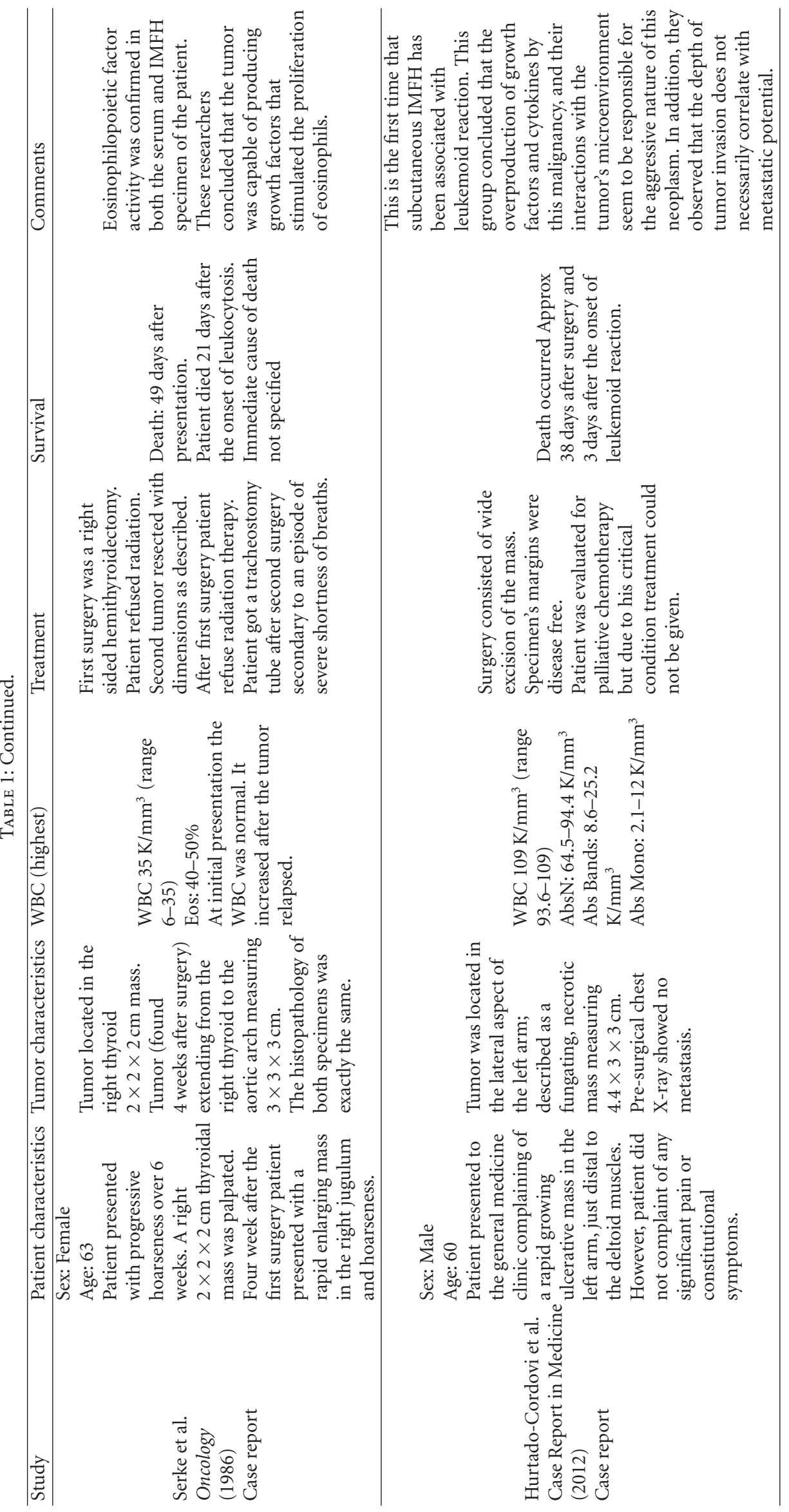




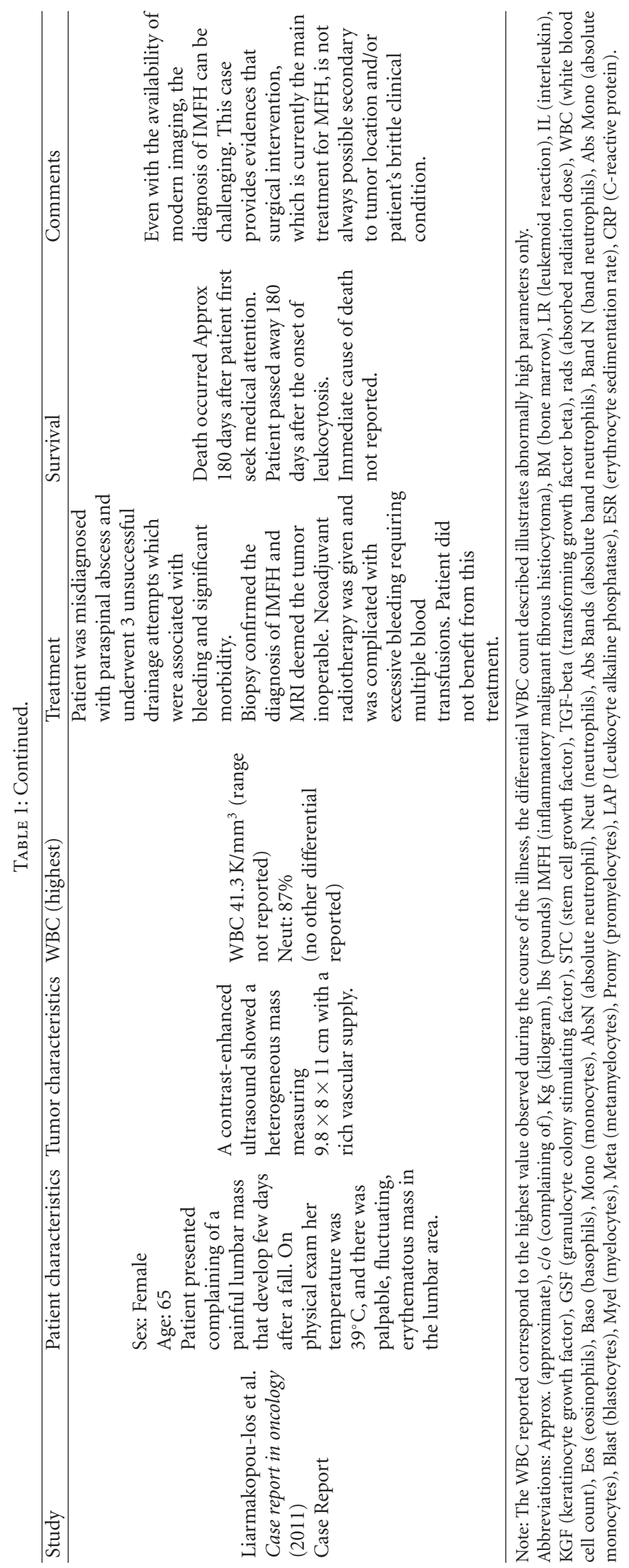


TABLE 2: Shows a brief summary of the results.

\begin{tabular}{ll}
\hline Total number of studies & 14 \\
\hline Total number of patients & 16 \\
Males: & $12(75 \%)$ \\
Females: & $4(25 \%)$ \\
Age: & 62.6 (range: $47-77)$ \\
\hline & Retroperitoneal: 8 cases (most common, 50\%) \\
& Abdominal cavity: 2 cases \\
Tumor location & Extremities/deep soft tissue: 3 cases \\
& Superficial: 1 case \\
\hline Most common complaint at presentation & Epididymis: 1 case \\
& Thyroid: 1 case \\
\hline Number of patients that passed away & Combination of mass/pain: 13 patients (81.2\%) \\
Numbers of patients alive at last follow up & Constitutional symptoms: 7 patients (43.8\%), \\
Overall Mean Survival & weight lost and fever being the most common. \\
\hline $\begin{array}{l}\text { Time of death after onset of LR/leukocytosis } \\
\text { (12 out 16 patients) }\end{array}$ & 12 \\
\hline
\end{tabular}

patient's tumor measured $10 \times 7 \times 4 \mathrm{~cm}$ and was located in the left thigh involving the muscles. The highest WBC registered was $38 \mathrm{~K} / \mathrm{mm}^{3}$. Patient treatment was delayed due to 4 none diagnostic biopsies; finally, the patient received an excisional biopsy which confirmed the diagnosis of IMFH associated with LR. Patient had radiation treatment which was complicated with erosion of the femoral artery resulting in massive hemorrhage necessitating emergent left thigh amputation. The surgical specimen was positive for metastatic foci in the deep soft tissue despite negative surgical margins and two tumor-free saphenous lymph nodes. These findings suggest that this tumor does not completely respond to radiotherapy, and that perhaps limb amputation results in long-term survival [13]. However, the morbidity and psychological impact associated with this procedure have to be considered especially since in this case, the surgery was done due to treatment complications and not with a curative intent. Kato et al. also reported a case in which the patient survived for 3 years after original diagnosis. The clinical course of this patient was characterized by multiple recurrences and aggressive surgical intervention each time. The highest $\mathrm{WBC}$ was $50.4 \mathrm{~K} / \mathrm{mm}^{3}$, and he was able to recover successfully from each surgical intervention [13]. It should be mentioned, that these two patients had no history of chronic debilitating diseases and had good functional statuses at disease presentation. Thus, these factors may have also played a role in the response to treatment.

It also seems that the location of the tumor has an impact on survival and response to treatment. Algabra et al. reported a case of IMFH associated with LR located in the right epididymis. Patient presented with pain, fever, and the highest WBC was $32.5 \mathrm{~K} / \mathrm{mm}^{3}$. Patient was treated aggressively with surgical removal of the right testicle followed by 10 cycles of chemotherapy (unfortunately the agents and doses were not specified), and local radiation with Cobalt ${ }^{60}$. Patient was alive and disease-free at last followup (Table 1) [17]. There were 8 patients diagnosed with retroperitoneal neoplasm of which 7 passed away, and only one survived. It is worth noting that the individual that survived was followed only for 180 days, which we considered to be a short period of time to label someone disease-free. This neoplasm has a high rate of local recurrence and metastasis, thus it is prudent to have a longer followup $[14,25]$. These observations suggest that when this malignancy arises from the retroperitoneum it has a higher recurrence rate and a poorer prognosis.

Our findings challenge the current view that depth of invasion at diagnosis correlates with metastatic potential $[2,16]$. We report a case of cutaneous IMFH associated with LR which at presentation was restricted to the dermis, had disease-free surgical margins, and a chest X-ray that was negative for any metastasis. However, the patient expired approximately 38 days after surgery with wide spread pulmonary metastasis [26]. This tumor also has a high recurrence rate, as portrayed by the case described by Takahashi et al. This patient had multiple recurrences and surgery before he finally succumbed to the disease approximately 35 days after the onset LR. Finally, it was also noted that in most cases, the severe leukemoid reaction was a sign of advanced disease and suggestive of a very poor prognosis. On the other hand, resolution of the LR/leukocytosis and normalization of inflammatory makers were associated with remission; once this malignancy relapses, these parameters increase once more $[9,12-17]$.

Treatment for this neoplasm remains mostly surgical; however, this approach is often precluded due to the age of the patients, advance stage of the disease at presentation, 
and comorbidities $[1,2,9,25,27,28]$. This tumor is not completely radiosensitive since relapses with wide spread metastasis have been observed after full courses of radiation, and deep soft tissue metastatic microfoci have been detected in surgical specimens after completion of radiation treatment $[1,9,13]$. The role of chemotherapy remains controversial; in our study, we found no clinical benefit or increase in overall survival with use of chemotherapy for metastatic and/or unresectable disease. However, it should be mentioned that in many of the cases described in this paper (Table 1) the fragile clinical condition of the patients precluded the use of intense chemotherapeutic plans. There have been reports of complete remission after the use of cyclophosphamide base chemotherapy in patients with IMFH not associated with LR. Poon et al. reported complete response to chemotherapy in four cases. The regimen consisted of cyclophosphamide in all cases, with additional doxorubicin, and methotrexate in the 1 st case, with vincristine, procarbazine, and prednisone in the 2nd case, with doxorubicin, vincristine and prednisone in the $3 \mathrm{rd}$, and with additional vincristine, and doxorubicin in the 4th case. They further suggested that inflammatory variant of malignant fibrous histiocytoma could be responsive to chemotherapy $[25,29,30]$. Phase II randomized trials conducted by The Sarcoma Alliance for Research Through Collaboration have shown that the combination of gemcitabine and docetaxel produced a $36 \%$ response rate (4 out 11 patients); this combination could be used for those patients refractory to cyclophosphamide/ifosfamidebased therapy. Unfortunately, this treatment was associated with significant pulmonary toxicity and refractory peripheral edema [31]. Early diagnosis of IMFH, preferably before the WBC reaches values above $50 \mathrm{~K} / \mathrm{mm}^{3}$, is crucial in order to entertain the possibility of aggressive chemotherapy with curative intent.

The exact reason responsible for the development of the LR/leukocytosis seen with this neoplasm remains unclear. However, it is now widely accepted that IMFH arises from a mesenchymal cell progenitor $[20,21]$. The predominant malignant cells seen in IMFH are primitive macrophages and/or histiocytes that retain the ability of cell division and phagocytosis. They can also release a variety of cytokines which correlate with their origin [9]. High levels of granulocyte colony-stimulating factor (G-CSF) have been detected in the serum of patients with IMFH associated with LR/leukocytosis (Table 1), as well as in other histological variants of this disease $[12,16,18,32,33]$. The role of G-CSF in the growth and progression of tumors remains controversial. Under normal homeostasis, it promotes the development of neutrophils which are a key component of the innate immune system. However, when G-CSF is overproduced by tumor cells, it has a tendency to encourage the development of what has been called myeloid-derived suppressor cells (MDSC) [34-39]. These immature immune cells are recruited from the bone marrow. They travel to the lymph nodes where dendritic cells prime $\mathrm{T}$ lymphocytes to mediate tumor cell elimination and hinder this process. The exact mechanism of how this is accomplished is still unknown; however, animal tumor models have shown that MDSC produce great quantities of reactive oxygen species
(ROS) and reactive nitrogen species such as Peroxynitrite. ROS prevent maturation of dendritic cells while promoting additional accumulation of MDSC, perpetrating further immune dysfunction. Peroxynitrite can diffuse across cells membranes and are capable of producing posttranslational modifications by nitration of amino acid residues such as tyrosine, cysteine, methionine, and tryptophan. These modifications affect the tridimensional structure of T-Cell receptors (TCR). This in turn decreases the binding affinity of cytotoxic $\mathrm{CD}^{+}{ }^{\text {'s }}$ TCR for MCH I peptide complex, weakening their ability to respond to antigen challenges [4042].

Animal models have also revealed that MDSC can also travel to tumors sites where they interfere with normal functioning of immune cells via the production of arginase 1. This enzyme rapidly depletes arginine from the tumor microenvironment which produces a severe inhibition of T-cell proliferation, diminish the expression of the CD3 zeta chain which is a key component of the TCR, and decreases the production of cytokines which promote tumor recognition and elimination. Simultaneous expression of arginase I and nitric oxide synthase (iNOS) by MDSC further enables them to restrain T-cell antitumor activity by stimulating the expression of these two pathways in nearby cells. They can also promote $\mathrm{T}$-cell apoptosis by means of increasing nitric oxide concentrations. MDSC are also found in the blood of cancer patients, and elevated activity of these two enzymes has been observed as well. In vitro studies have shown that depletion of these cells from the circulatory system of these patients restores normal function of peripheral lymphocytes. Lastly, MDSC also produce and stimulate the production of cytokines such as IL 4 and IL 13 among others. These molecules promote tumor escape by encouraging the differentiation of $\mathrm{T}$ suppressor lymphocytes from precursor cells. In turn, $\mathrm{T}$ suppressor lymphocytes induce immunotolerance and anergia in tumor infiltrating lymphocytes. These observations suggest that MDSC have an active role in promoting immune cell dysfunction in the tumor microenvironment as well as in the peripheral circulation of cancer patients [41-43]. Other inflammatory cytokines such as IL-6, IL-7, IL-8, transforming growth factor beta (TGF-beta), and stem colony-stimulating factor (SCF), are present at abnormally high levels in the serum of patients with this neoplasm. Animal models have shown that IL6 can sustain neutrophil and macrophage colonies, and through its action on other immune cells, it can stimulate the bone marrow to produce other growth factors. Interlukin-7 induces proliferation of lymphocytes; it also increases WBC by stimulating secretion of IL-1, IL-6, and tumor necrosis (TNF) factor from peripheral lymphocytes, monocytes, and macrophages. Interlukin- 8 is a potent neutrophilic chemotactic and activating cytokine; thus it may contribute to the severe inflammatory infiltrate seen in IMFH lesions $[9,44,45]$.

Under normal physiological conditions, TGF-beta controls key cell functions such as proliferation, differentiation, and it also promotes extracellular matrix formation and tissue repair. Generally speaking, TGF-beta inhibits proliferation of epithelial cells, and it encourages growth of 
some mesenchymal cell subsets; however, its concentration as well as the density of its receptors has been found to be overexpressed in many solid malignancies. This observation has lead researchers to believe that it may play a central role in the development and growth of tumors. Yamamoto et al. investigated the expression of TGF-beta isoforms and their receptors in 43 human $\mathrm{MFH}$ specimens. In this study, all the samples expressed different isoforms of this growth factor. On the other hand, 84 percent of these cells expressed TGF beta receptor type 1 (R1), 56\% were positive for TGF beta R2, and $53 \%$ of them stained for both. These researchers compared the growth rate of $\mathrm{MFH}$ cells positive for both receptors with those positive only for one. They found that the MIB-1 proliferation index in the MFH cell line positive for both receptors was considerably higher than in those cells positive for a single one. This result suggests that the interactions of these receptors with their ligands have an important role in supporting the proliferation of MFH cells likely through an autocrine and/or paracrine mechanism. Thus, further description of the TGB R1 and R2 coexpression may aid oncologists in predicting the behavior of this tumor $[46,47]$. Thus, we conclude that the high concentration of GCSF, TGF-beta, inflammatory cytokines, and the abundant inflammatory infiltrate associated with this malignancy does not necessarily translate into an effective immune response; instead, these biomolecules and immature immune cells may be promoting the growth and aggressive nature of this neoplasm.

SCF along with other grow factors act on the BM to increase the number of circulating erythrocytes, neutrophils, lymphocytes, monocytes, eosinophils, and basophils; it also contributes to the hypercellular BM observed in patients with this illness. The soluble and membrane-bound forms of SCF messenger RNAs have been detected in MFH cell lines. Membrane-bound SCF increases the stability of its receptor tyrosine-protein kinase Kit (c-Kit), thus avoiding cKit-down regulation and promoting longer Kinase activity. In addition, this membrane-bound form facilitates cell-tocell adhesion by interacting with its receptor kinase, and since it has a cellular domain, it could also be capable of signal transduction either by itself or in conjunction with other biomolecules. Its soluble counterpart fulfills similar functions but is less potent. Based on these observations, researchers have theorized that the interactions between this growth factor with its receptor may sustain the development of these malignant cells likely through a paracrine mechanism $[48,49]$.

Other investigators disagree with this theory since they have found very low concentrations of c-Kit in MFH cell lines [50]. Under normal circumstances, SCF promotes the differentiation and development of mast cells and also induces the production of platelet-derived growth factor (PDGF), basic fibroblastic grow factor, vascular endothelial growth factor, among others by these cells. It is also known that c-Kit is structurally and functionally related to the PDGF receptor. It may be possible that increased manufacturing of SCF by these malignant cells could promote the production of these angiogenic substances which indirectly will promote the development and the metastatic potential of this neoplasm. This statement is supported by Taniuchi et al. which suggested that proliferation of these malignant cells could be mediated via an autocrine or paracrine pathway through PDGF receptors [51, 52]. In addition, animal studies have shown that tumor infiltrating MDSC along with other immature immune cells which are also part of the tumor's microenvironment can increase the bioavailability of PDGF. This growth factor has powerful angiogenic properties and promotes tumor growth and neovascularization through expression of metalloproteinase 9 by myeloid cells. Thus, SCF through direct and/or indirect actions could be one of the main culprits responsible for aggressive behavior display by this malignancy [53].

We speculated that since SCF and PDGF-beta seem to encourage the growth of this tumor through interactions with receptors on tumor cells and/or bystander cells; the thought of blocking of these receptors with multiselective kinase inhibitors such as imatinib or sunitinib could be entertained. These drugs can inhibit PDGF receptor kinase, Abl kinase, and the c-Kit receptor. Thus, they could theoretically prevent the interaction of these growth factors with their target and serve as an adjuvant therapy. This theory is supported by Irsan et al.'s results. These researchers demonstrated the expression of PDGF and c-Kit mRNA in 3 of their $4 \mathrm{MFH}$ cell lines. These cells were cultured and transplanted into mice, thus creating a Xenograft model. Imatinib was found to inhibit tumor growth in those $\mathrm{MFH}$ cells that were positive for PDGF and c-Kit receptor, but not in those that were negative. This group concluded that imatinib may work by preventing phosphorylation at the kinase receptor domain. On the other hand, sunitinib in particular has shown activity against other solid tumors, even in cases of gastrointestinal stromal tumors with documented resistance to imatinib. Mahmood et al. conducted a single institution phase II trial to investigate the safety and efficacy of this Kinase inhibitor in 3 types of sarcomas including $\mathrm{MFH}$. The patients in this trial had metastatic or unresectable disease. This team found a median progression-free survival and overall free survival of 4.2 and 13.6 months, respectively. Unfortunately, their data failed to reach any statistical significance, and they could not show any significant increase in overall response. However, there were confounders in this research that could have affected the outcome; namely, a heavily pretreated population and patients with indolent malignancy. Thus, we believe that further study of these agents with a larger sample size and in a randomized pattern is warranted $[54,55]$.

IMFH associated with LR carries an overall poor prognosis. The presence of LR occurs once there is advanced disease, and it suggests a dismal prognosis. The tumor does not completely respond to XRT and we did not observe any clinical benefits whenever chemotherapy was used likely secondary to the brittle clinical condition of the patients. Further studies of multiselective kinase inhibitors such as imatinib and sunitinib are warranted since they have shown some activity against this malignancy; however, they should be done in bigger sample size population and in a randomized pattern. Early detection and accurate diagnosis is crucial in order to attempt chemotherapy with curative 
intents. Overproduction of growth factors and cytokines by IMFH cells and their interactions with the inflammatory infiltrate seem to promote immunological effector cell's dysfunction and substantiate the development and growth of this neoplasm. Thus, more research is needed to understand the exact mechanism of how these substances favor the progression of these neoplastic cells. This will eventually lead to the identification of molecular targets for treatment.

\section{Abbreviations}

\begin{tabular}{|c|c|}
\hline Approx.: & Approximate \\
\hline c/o: & (Complaining of) \\
\hline Kg: & (Kilogram) \\
\hline lbs: & (Pounds) \\
\hline IMFH: & $\begin{array}{l}\text { (Inflammatory malignant fibrous } \\
\text { histiocytoma) }\end{array}$ \\
\hline BM: & (Bone marrow) \\
\hline LR: & (Leukemoid reaction) \\
\hline IL: & (Interleukin) \\
\hline KGF: & (Keratinocyte growth factor) \\
\hline GSF: & $\begin{array}{l}\text { (Granulocyte colony-stimulating } \\
\text { factor) }\end{array}$ \\
\hline STC: & (Stem cell growth factor) \\
\hline TGF-beta: & (Transforming growth factor beta) \\
\hline Rads: & (Absorbed radiation dose) \\
\hline WBC: & (White blood cell count) \\
\hline Eos: & (Eosinophils) \\
\hline Baso: & (Basophils) \\
\hline Mono: & (Monocytes) \\
\hline AbsN: & (Absolute neutrophil) \\
\hline Neut: & (Neutrophils) \\
\hline Abs Bands: & (Absolute band neutrophils) \\
\hline Band N: & (Band neutrophils) \\
\hline Abs Mono: & (Absolute monocytes) \\
\hline Blast: & (Blastocytes) \\
\hline Myel: & (Myelocytes) \\
\hline Meta: & (Metamyelocytes) \\
\hline Promy: & (Promyelocytes) \\
\hline LAP: & (Leukocyte alkaline phosphatase) \\
\hline ESR: & (Erythrocyte sedimentation rate) \\
\hline CRP: & (C-reactive protein). \\
\hline
\end{tabular}

\section{Acknowledgment}

A very special thanks are due to Dr. Vardaros who kindly put her research expertise to our disposition.

\section{References}

[1] M. Kyriakos and R. L. Kempson, "Inflammatory fibrous histiocytoma, an aggressive and lethal lesion," Cancer, vol. 37, no. 3, pp. 1584-1606, 1976.

[2] D. S. Weiss and F. M. Enzinger, "Malignant fibrous histiocytoma: an analysis of 200 cases," Cancer, vol. 41, no. 6, pp. 2250 2266, 1978.

[3] Y. Oda, S. Tamiya, Y. Oshiro et al., "Reassessment and clinicopathological prognostic factors of malignant fibrous histiocytoma of soft parts," Pathology International, vol. 52, no. 9, pp. 595-606, 2002.
[4] D. M. C. Fletcher, "Pleomorphic malignant fibrous histiocytoma: fact or fiction? A critical reappraisal based on 159 tumors diagnosed as pleomorphic sarcoma," American Journal of Surgical Pathology, vol. 16, no. 3, pp. 213-228, 1992.

[5] M. D. Murphey, "World Health Organization classification of bone and soft tissue tumors: modifications and implications for radiologists," Seminars in Musculoskeletal Radiology, vol. 11, no. 3, pp. 201-214, 2007.

[6] C. A. Moran, S. Suster, G. Perino et al., "Malignant smooth muscle tumors presenting as mediastinal soft tissue masses. A clinicopathologic study of 10 cases," Cancer, vol. 74, pp. 22512260, 1994.

[7] Wintrobe's Clinical Hematology, vol. 2, 10th edition, 1999.

[8] Hoffman Hematology Basic Principles and Practice, 5th edition, 2008.

[9] M. F. Melhem, A. L. Meisler, R. Saito, G. G. Finley, H. R. Hockman, and R. A. Koski, "Cytokines in inflammatory malignant fibrous histiocytoma presenting with leukemoid reaction," Blood, vol. 82, no. 7, pp. 2038-2044, 1993.

[10] S. Serke, M. Brenner, R. Zimmermann, and H. Lobeck, "Malignant fibrous histiocytoma associated with peripheral blood eosinophilia. In vitro studies demonstrating tumorderived eosinophilopoietic activity," Oncology, vol. 43, no. 4, pp. 230-233, 1986.

[11] J. R. Vilanova, J. Burgos-Bretones, R. Simon, and J. M. RiveraPomar, "Leukaemoid reaction and eosinophilia in 'inflammatory fibrous histiocytoma," Virchows Archiv-Abteilung A Pathologische Anatomie, vol. 388, no. 2, pp. 237-243, 1980.

[12] T. Kato, T. Kojima, T. Shimizu et al., "Inflammatory malignant fibrous histiocytoma of the gallbladder: report of a case," Surgery Today, vol. 32, no. 1, pp. 81-85, 2002.

[13] J. E. Asirwatham and J. W. Pickeren, "Inflammatory fibrous histiocytoma, case report," Cancer, vol. 41, no. 4, pp. 14671471, 1978.

[14] S. Ballesttri, L. Losi, M. Favali et al., "Hypervascular retroperitoneal mass in a patient with fever and leucocytosis-contrastenhanced-ultrasonographic findings in a case of inflammatory malignant fibrous histiocytoma," European Journal of Ultrasound, vol. 32, pp. 1-4, 2011.

[15] A. W. W. Roques, L. W. L. Horton, J. Leslie, and M. S. BuxtonThomas, "Inflammatory fibrous histiocytoma in the left upper abdomen with a leukemoid blood picture," Cancer, vol. 43, no. 5, pp. 1800-1804, 1979.

[16] K. Takahashi, Y. Kimura, M. Naito, T. Yoshimura, H. Uchida, and S. Araki, "Inflammatory fibrous histiocytoma presenting leukemoid reaction," Pathology Research and Practice, vol. 184, no. 5, pp. 498-506, 1989.

[17] F. Algaba, I. Trias, and C. Castro, "Inflammatory malignant fibrous histiocytoma of the spermatic cord with eosinophilia," Histopathology, vol. 14, no. 3, pp. 319-321, 1989.

[18] M. Hisaoka, S. Tsuji, H. Hashimoto, T. Aoki, and K. Uriu, "Dedifferentiated liposarcoma with an inflammatory malignant fibrous histiocytoma-like component presenting a leukemoid reaction," Pathology International, vol. 47, no. 9, pp. 642-646, 1997.

[19] J. M. Ruiz Liso and J. R. Garcia, "Fibroushistiocitoma maligno "Inflammatorio" de cordon espermatico con infiltracion sobre un leiomioma inguinal. Presentacion de 1 caso con revision conceptual y de la literature," Archivos Españoles de Urología, vol. 61, pp. 485-498, 2008.

[20] I. Matushansky, E. Hernando, N. D. Socci et al., "Derivation of sarcomas from mesenchymal stem cells via inactivation of the Wnt pathway," The Journal of Clinical Investigation, vol. 117, no. 11, pp. 3248-3257, 2007. 
[21] I. Matushansky, E. Charytonowicz, J. Mills, S. Siddiqi, T. Hricik, and C. Cordon-Cardo, "MFH classification: differentiating undifferentiated pleomorphic sarcoma in the 21st century," Expert Review of Anticancer Therapy, vol. 9, no. 8, pp. 1135-1144, 2009.

[22] J. Samejima, K. Takahashi, T. Omori, K. Okudela, M. Tajiri, and M. Masuda, "Inflammatory malignant fibrous histiocytoma of thymus origin," Annals of Thoracic Surgery, vol. 89, no. 6, pp. 2003-2005, 2010.

[23] I. Murata, K. Makiyama, K. Miyazaki et al., "A case of inflammatory malignant fibrous histiocytoma of the colon," Gastroenterologia Japonica, vol. 28, no. 4, pp. 554-563, 1993.

[24] S. K. Singh, A. K. Mandal, M. M. Agarwal, and A. Das, "Primary renal inflammatory malignant fibrous histiocytoma: a diagnostic challenge," International Journal of Urology, vol. 13, no. 7, pp. 1000-1002, 2006.

[25] M.-C. Poon, J. R. Durant, M. J. Norgard, and V. Y. H. ChangPoon, "Inflammatory fibrous histiocytoma: an important variant of malignant fibrous histiocytoma highly responsive to chemotherapy," Annals of Internal Medicine, vol. 97, no. 6, pp. 858-863, 1982.

[26] J. Hurtado-Cordovi, B. Avezbakiyev, M. Frieri, L. Freedman, and W. Gebre, "Cutaneous inflammatory malignant fibrous histiocytoma presenting with a leukemoid reaction: a case report and review of the literature," Case Report in Medicine, vol. 2012, Article ID 798629, 5 pages, 2012.

[27] G. Virgili, S. M. Di Stasi, L. Storti, A. Orlandi, and G. Vespasiani, "Successful management of retroperitoneal malignant fibrous histiocytoma involving both kidneys," Scandinavian Journal of Urology and Nephrology, vol. 34, no. 3, pp. 208-210, 2000.

[28] E. Liarmakopoulos, P. Lampropoulos, A. Marinis et al., "Soft tissue paraspinal inflammatory malignant fibrous histiocytoma presenting as a lumbar abscess," Case Reports in Oncology, vol. 4, no. 2, pp. 343-349, 2011.

[29] A. Ferlito, P. Nicolai, G. Recher, and S. Narne, "Primary laryngeal malignant fibrous histiocytoma: review of the literature and report of seven cases," Laryngoscope, vol. 93, no. 10, pp. 1351-1358, 1983.

[30] K. Shinjo, "Analysis of prognostic factors and chemotherapy of malignant fibrous histiocytoma of soft tissue: a preliminary report," Japanese Journal of Clinical Oncology, vol. 24, no. 3, pp. 154-159, 1994.

[31] R. G. Maki, "Gemcitabine and docetaxel in metastatic sarcoma: past, present, and future," The Oncologist, vol. 12, no. 8, pp. 999-1006, 2007.

[32] E. Mayumi, T. Okuno, T. Ogawa et al., "Malignant fibrous histiocytoma of soft tissue producing granulocyte colonystimulating factor," Internal Medicine, vol. 40, no. 6, pp. 536540,2001

[33] F. Jardin, M. Vasse, M. Debled et al., "Intense paraneoplastic neutrophilic leukemoid reaction related to a G-CSF-secreting lung sarcoma," American Journal of Hematology, vol. 80, no. 3, pp. 243-245, 2005.

[34] P. Serafini, I. Borrello, and V. Bronte, "Myeloid suppressor cells in cancer: recruitment, phenotype, properties, and mechanisms of immune suppression," Seminars in Cancer Biology, vol. 16, no. 1, pp. 53-65, 2006.

[35] P. Goedegebuure, J. B. Mitchem, M. R. Porembka et al., "Myeloid-derived suppressor cells: general characteristics and relevance to clinical management of pancreatic cancer," Current Cancer Drug Targets, vol. 11, no. 6, pp. 734-751, 2011.

[36] C. Meyer, A. Sevko, M. Ramacher et al., "Chronic inflammation promotes myeloid-derived suppressor cell activation blocking antitumor immunity in transgenic mouse melanoma model," Proceedings of the National Academy of Sciences of the United States of America, vol. 108, pp. 1711-1716, 2011.

[37] J. K. Morales, M. Kmieciak, K. L. Knutson, H. D. Bear, and M. H. Manjili, "GM-CSF is one of the main breast tumor-derived soluble factors involved in the differentiation of CD11b-Gr1bone marrow progenitor cells into myeloid-derived suppressor cells," Breast Cancer Research and Treatment, vol. 123, no. 1, pp. 39-49, 2010.

[38] M. G. Lechner, D. J. Liebertz, and A. L. Epstein, "Characterization of cytokine-induced myeloid-derived suppressor cells from normal human peripheral blood mononuclear cells," The Journal of Immunology, vol. 185, no. 4, pp. 2273-2284, 2010.

[39] I. Younos, M. Donkor, T. Hoke et al., "Tumor- and organdependent infiltration by myeloid-derived suppressor cells," International Immunopharmacology, vol. 11, no. 7, pp. 816826, 2011.

[40] L. L. Marigo, L. Dolcetti, P. Serafini, P. Zanovello, and V. Bronte, "Tumor-induced tolerance and immune suppression by myeloid derived suppressor cells," Immunological Reviews, vol. 222, no. 1, pp. 162-179, 2008.

[41] T. L. Whiteside, "Immune responses to malignancies," Journal of Allergy and Clinical Immunology, vol. 125, no. 2, pp. S272S283, 2010.

[42] J. D. Waigh, Q. Hu, A. Miller et al., "Tumor-derived G-CSF facilitates neoplastic growth through a granulocytic myeloidderived suppressor cell-dependent mechanism," PLoS One, vol. 6, Article ID e27690, 2011.

[43] A. C. Ochoa, A. H. Zea, C. Hernandez, and P. C. Rodriguez, "Arginase, prostaglandins, and myeloid-derived suppressor cells in renal cell carcinoma," Clinical Cancer Research, vol. 13, no. 2, pp. 721-726, 2007.

[44] S. Osaka, S. Hayakawa, Y. Yoshida, E. Sakurada, J. Ryu, and M. Sugitani, "Interleukin-8 producing malignant fibrous histiocytoma with prolonged fever," Acta Histochemica et Cytochemica, vol. 39, no. 1, pp. 17-21, 2006.

[45] Y. Yamakawa, M. Fujimura, T. Hidaka, K. Yasoshima, and S. Saito, "Inflammatory malignant fibrous histiocytoma of the ovary producing interleukin-6: a case report," Gynecologic Oncology, vol. 75, no. 3, pp. 484-489, 1999.

[46] T. Yamamoto, T. Akisue, T. Marui et al., "Expression of transforming growth factor $\beta$ isoforms and their receptors in malignant fibrous histiocytoma of soft tissues," Clinical Cancer Research, vol. 10, no. 17, pp. 5804-5807, 2004.

[47] J. A. Wright, E. A. Turley, and A. H. Greenberg, "Transforming growth factor beta and fibroblast growth factor as promoters of tumor progression to malignancy," Critical Reviews in Oncogenesis, vol. 4, no. 5, pp. 473-492, 1993.

[48] T. Nakatani, T. Marui, T. Yamamoto et al., "Expression of stem cell factor and c-kit in human malignant fibrous histiocytoma cell line (TNMY1)," Anticancer Research, vol. 23, no. 3, pp. 2329-2333, 2003.

[49] K. E. Langley, L. G. Bennett, J. Wypych et al., "Soluble stem cell factor in human serum," Blood, vol. 81, no. 3, pp. 656-660, 1993.

[50] T. Yamamoto, T. Nakatani, T. Marui et al., "Expression of stem cell factor and lack of c-kit expression in malignant fibrous histiocytoma of soft tissues," Anticancer Research, vol. 23, no. 5, pp. 4305-4308, 2003.

[51] K. Taniuchi, Y. Yamada, A. Nonomura, and K. Takehara, "Immunohistochemical analysis of platelet-derived growth factor and its receptors in fibrohistiocytic tumors," Journal of Cutaneous Pathology, vol. 24, no. 7, pp. 393-397, 1997. 
[52] A. Abdiu, T. M. Walz, B. K. Nishikawa, S. Wingren, S. E. Larsson, and $\AA$. Wasteson, "Human malignant fibrous histiocytomas in vitro: growth characteristics and their association with expression of mRNA for platelet-derived growth factor, transforming growth factor-alpha and their receptors," European Journal of Cancer, vol. 34, no. 13, pp. 2094-2100, 1998.

[53] G.-O. Ahn and J. M. Brown, "Matrix metalloproteinase-9 is required for tumor vasculogenesis but not for angiogenesis: role of bone marrow-derived myelomonocytic cells," Cancer Cell, vol. 13, no. 3, pp. 193-205, 2008.

[54] I. Irsan, T. Akisue, H. Hara et al., "Imatinib mesylate inhibits tumorigenicity of malignant fibrous histiocytoma cells in vivo," Anticancer Research, vol. 27, no. 1, pp. 423-430, 2007.

[55] S. T. Mahmood, S. Agresta, C. Vigil et al., "Phase II study of sunitinib malate, a multitargeted tyrosine kinase inhibitor in patients with relapsed or refractory soft tissue sarcomas. Focus on three prevalent histologies: leiomyosarcoma, liposarcoma and malignant fibrous histiocytoma," International Journal of Cancer, vol. 129, no. 8, pp. 1963-1969, 2011. 


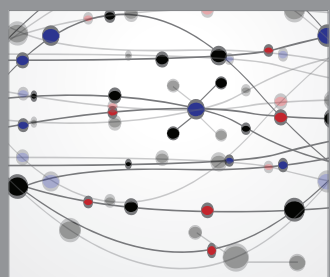

The Scientific World Journal
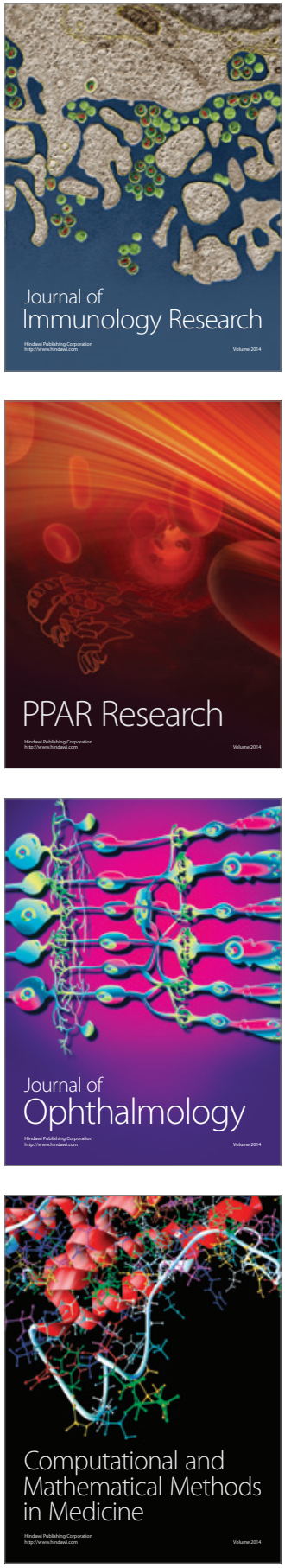

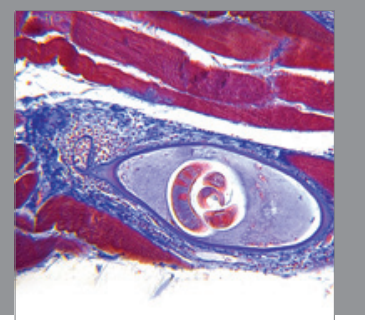

Gastroenterology

Research and Practice
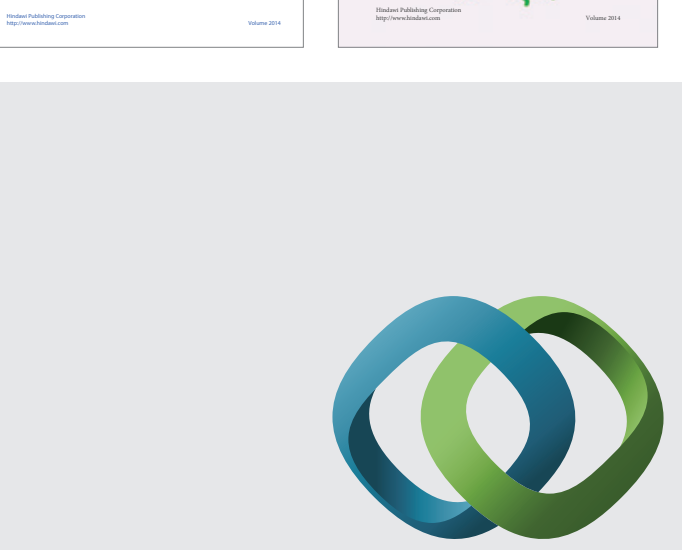

\section{Hindawi}

Submit your manuscripts at

http://www.hindawi.com
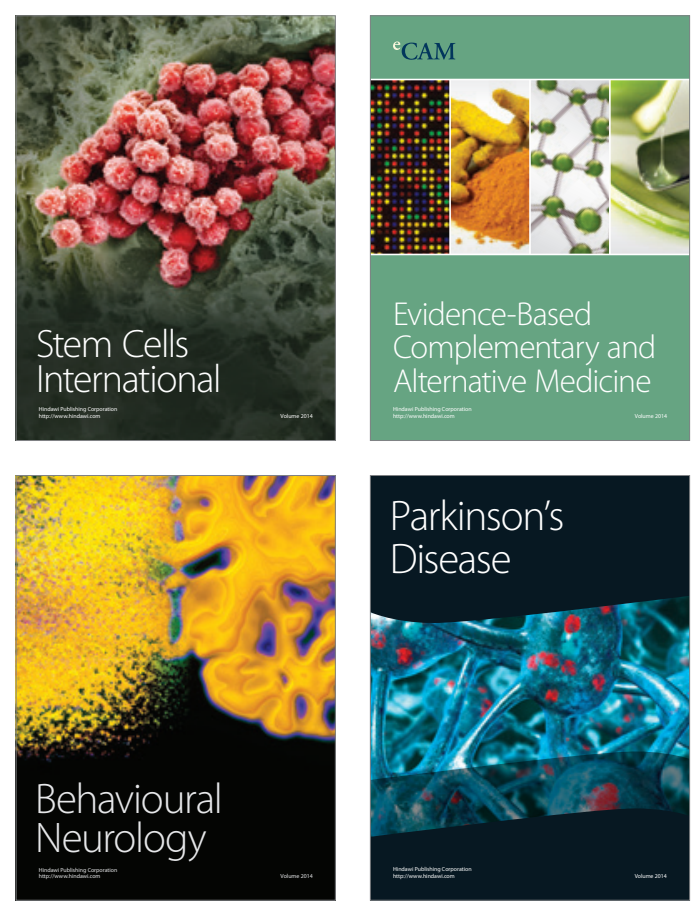

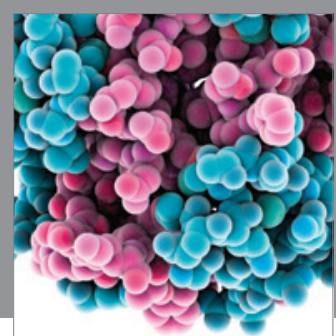

Journal of
Diabetes Research

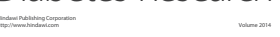

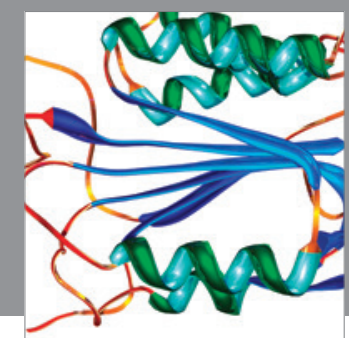

Disease Markers
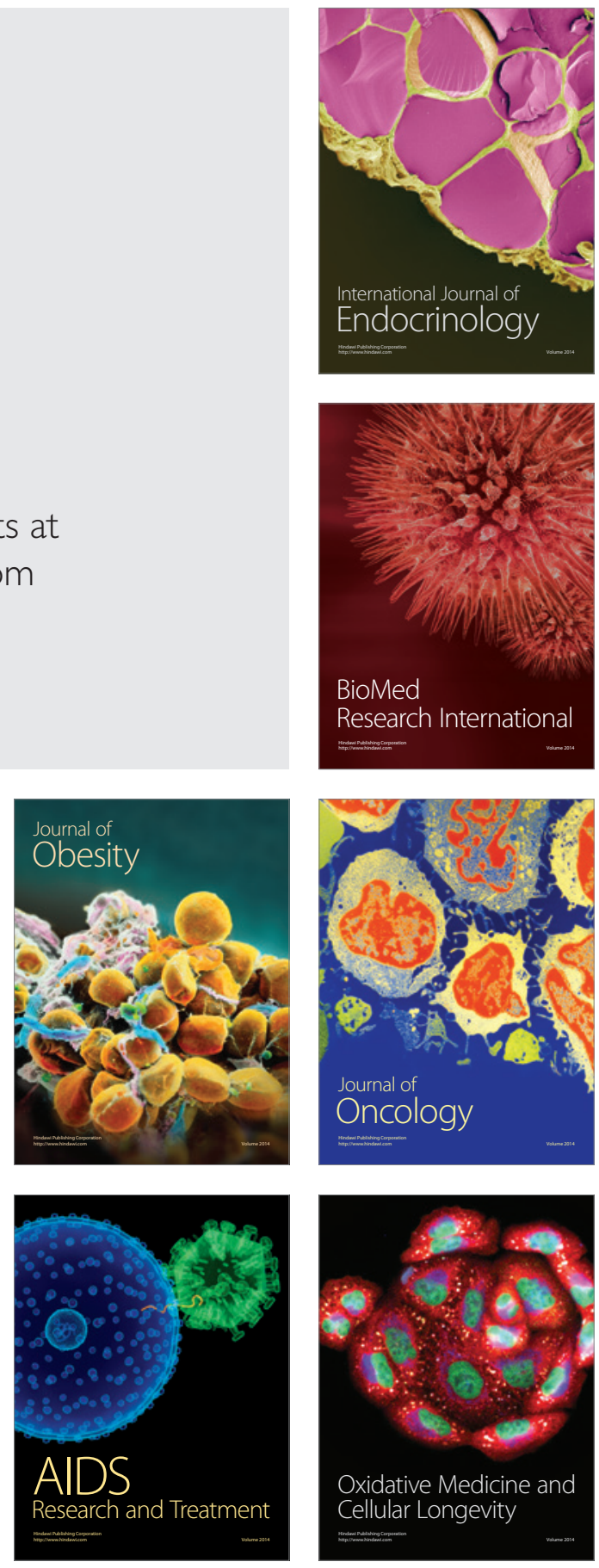